Article

\title{
Learning Science during Teatime: Using a Citizen Science Approach to Collect Data on Litter Decomposition in Sweden and Austria
}

\author{
Taru Sandén ${ }^{1, *} \mathbb{1}$, Heide Spiegel ${ }^{1}\left(\mathbb{D}\right.$, Hannah Wenng ${ }^{1,2,3}$, Michael Schwarz $^{4}$ and \\ Judith M. Sarneel ${ }^{5,6}$ \\ 1 Department for Soil Health and Plant Nutrition, Austrian Agency for Health and Food Safety (AGES), \\ Spargelfeldstrasse 191, 1220 Vienna, Austria; adelheid.spiegel@ages.at (H.S.); \\ hannah.wenng@nibio.no (H.W.) \\ 2 Norwegian Institute for Bioeconomy Research (NIBIO), P.O. Box 115, 1431 Ås, Norway \\ 3 Faculty of Environmental Science and Natural Resource Management, Norwegian University of Life \\ Science (NMBU), Fougnerbakken 3, 1432 Ås, Norway \\ 4 Department for Data Management, Austrian Agency for Health and Food Safety (AGES), Spargelfeldstrasse \\ 191, 1220 Vienna, Austria; michael.schwarz@ages.at \\ 5 Department of Ecology and Environmental Science, Umeå University, Tvistevägen 48, 90187 Umeå, Sweden; \\ judith.sarneel@umu.se \\ 6 Ecology \& Biodiversity Group and Plant Ecophysiology Group, Utrecht University, Padualaan 8, \\ 3584 CH Utrecht, The Netherlands \\ * Correspondence: taru.sanden@ages.at; Tel.: +43-50555-34133
}

Received: 2 September 2020; Accepted: 17 September 2020; Published: 18 September 2020

check for updates

\begin{abstract}
The decay of organic material-litter decomposition—is a critical process for life on Earth and an essential part of the global carbon cycle. Yet, this basic process remains unknown to many citizens. The Tea Bag Index (TBI) measures decomposition in a standardized, measurable, achievable, climate-relevant, and time-relevant way by burying commercial tea bags in soil for three months and calculating proxies to characterize the decomposition process (expressed as decomposition rate $(\mathrm{k})$ and stabilization factor (S)). We measured TBI at $8 \mathrm{~cm}$ soil depth with the help of school and farm citizen scientists in 2015 in Sweden and in 2016 in Austria. Questionnaires to the participating schools and farms enabled us to capture lessons learned from this participatory data collection. In total $>5500$ citizen scientists participated in the mass experiments, and approximately $50 \%$ of the tea bags sent out yielded successful results that fell well within previously reported ranges. The average decomposition rates $(k)$ ranged from 0.008 to $0.012 \mathrm{~g} \mathrm{~d}^{-1}$ in Sweden and from 0.012 to $0.015 \mathrm{~g} \mathrm{~d}^{-1}$ in Austria. Stabilization factors (S) were up to four times higher in Sweden than Austria. Taking part in a global experiment was a great incentive for participants, and in future experiments the citizen scientists and TBI would benefit from having enhanced communication between the researchers and participants about the results gained.
\end{abstract}

Keywords: Tea Bag Index (TBI); participatory research; hands-on science experience; citizen scientists' motivation

\section{Introduction}

Soil is a key resource that is pivotal for our existence by providing numerous ecosystem services, such as food, fibre and fuel production, water purification, habitat for diverse organisms, nutrient recycling, and carbon sequestration [1,2]. Soils and soil organic matter (SOM) are the basis of terrestrial life [3]. SOM is a main part of the carbon cycle. Around $80 \%$ of the terrestrial organic carbon stock 
is bound in soils, only $20 \%$ in plant biomass [3,4]. Decomposition, which determines the return of plant residues (e.g., litter) to the soil, can be characterized by the decomposition rate and stabilization of the labile material fraction of the litter [5]. The interactions between the biotic breakdown of litter (by microbial communities) and the abiotic drivers of decomposition speed (chemical and physical soil parameters) are crucial for SOM accumulation and turnover, but not yet fully understood across large climatic gradients $[3,5,6]$. The influence of these interactions is therefore of major interest for understanding, predicting, and modeling carbon cycle responses to environmental changes at different scales (local, national, global). These interactions are also crucial in maintaining of a balanced carbon cycle and in preserving species and soil functions [3].

The Tea Bag Index (TBI) [7] involves citizens alongside with researchers in generating new knowledge on litter decomposition across the globe. So far, citizen scientists have mostly been included in projects focusing on plant and animal species and less so on soil science [8]. Although major soil awareness campaigns have been organized in recent years, knowledge about the importance of litter decomposition is lacking among the general public. This lack of awareness about soil hampers political incentives for national and international policy-makers to take measures needed for a sustainable use of this key natural resource. Furthermore, better soil awareness would help prevent careless use of the soil by the general public. Projects using the concept of citizen science enable win-win situations for both scientists and volunteers. For the scientists, citizen science allows data collection in larger geographic areas, over sustained periods of time, and can reduce staff costs [8-10]. Equally, involvement in a scientific process enables citizen scientists to raise awareness and gain knowledge on the complexity of soils through hands-on methods $[9,11]$. Ensuring the data quality is the main critique against citizen science as a method [12-15]. The concept of verified citizen science is a solution designed to minimize the error in the collected data by using data confirmed by experts $[8,10,13]$. Previous studies on plant litter have shown that that the combination of moisture and temperature can explain $50-70 \%$ of the variation in decomposition [7,16-18]. Beyond yielding new knowledge on litter decomposition processes, data on litter decomposition can also be used to increase the predictive power of climate/environmental models. Currently, however, there is a lack of higher resolution measurements that would strongly improve these models $[7,19,20]$.

This study is designed to investigate litter decomposition across six environmental zones in Sweden and Austria, in cooperation with $>4000$ Swedish and 1500 Austrian citizen scientists. Specifically, our objective is to study how litter decomposition rates $(k)$ and stabilization factors $(S)$ are affected by 1) experimental warming across the climate gradient in Sweden, and 2) land use (maize field, forest, and grassland) in Austria. We also examine the motivations of citizen scientists to contribute to a research project. To answer these questions, we conduct two mass experiments, one with teachers and school pupils as citizen scientists in Sweden in 2015, and one with school pupils and their teachers, groups, and individual farmers as citizen scientists in Austria in 2016.

\section{Materials and Methods}

\subsection{Citizen Science Experiments}

\subsubsection{Standard Tea Bag Index (TBI) Protocol}

The decomposition rate $(k)$ and the litter stabilization factor $(\mathrm{S})$ were assessed using the Tea Bag Index (TBI) method [7]. This standardized method used green tea (EAN 872270005552 5) and rooibos tea (EAN 872270018843 8) produced by Lipton (Unilever) in $0.25 \mathrm{~mm}$ woven, nylon mesh bags. Green and rooibos tea bags were weighed and buried pairwise at a depth of $8 \mathrm{~cm}$. After three months the tea bags were retrieved, cleaned of adhering soil particles, and dried for at least three days on a warm dry location before re-weighing. Mass loss (ML) of the tea was calculated as the weight lost inside the tea bag by ML $=(\mathrm{SW}-\mathrm{FW}) /(\mathrm{SW}-\mathrm{B})$, where $\mathrm{SW}$ is the initial weight, $\mathrm{FW}$ the final weight after incubation, and B the mass of the bag at the start of the experiment. Using the mass losses of green tea and rooibos, we calculated $k$ and $\mathrm{S}$ as in [7]. 


\subsubsection{Sweden-Warming Effects}

A call was made in February 2015 to teachers who were part of the network of the Swedish Forskar Fredag. In March 2015, 520 school classes applied to take part in the experiment. Due to budgetary constraints, only 250 classes were selected to participate. The selection was based on a suitable geographic distribution of participating schools, and included classes from primary to upper secondary school (pupils age 6-19 years). In early May 2015, schools were provided with tea bags (six green and six rooibos), a digital scale, two pre-programmed temperature sensors, a soil sampling device, a data form for results and observations, and an instruction booklet (https: //forskarfredag.se/forskarfredags-massexperiment/tepaseforsoket-2015/). Three instruction videos were posted on YouTube (how to use the scale, how to take a soil sample, and how to do the experiment), receiving about 900 views per video. Almost all schools started the experiment in late May-early June.

In the Swedish experiment, participants aimed to test the effect of warming on decomposition. Participants were free to select the experimental site, as long as it was a field dominated by grass species. Following the standard TBI protocol, the pupils buried six green and six rooibos tea bags in total, consisting of three replicate blocks of four bags (two green and two rooibos) each. A warming treatment was applied to half of the bags by placing an $11 \mathrm{~cm}$ long plastic cylinder (volume ca $700 \mathrm{~cm}^{3}$ ) made by cutting off the top and bottom of a fully transparent PET bottle (Loka, Spendrups bryggeri $\mathrm{AB}, \mathrm{Vå}$ rby) over those tea bags. The temperature sensors were also buried following the standard protocol, in an extra block with a PET cylinder placed over one of the sensors. At each block where tea bags were buried, one soil sample of $15 \mathrm{~cm}^{3}$ was taken. A mixed and air-dried subsample was sent back to the researchers at Umeå University.

The experiment was completed at the end of August 2015, and 63\% of the schools returned the soil temperature sensor and a soil sample together with the completed data form. After analyzing the soil samples, temperature data, and the tea bag data, feedback was provided to the classes in a final popular science report and a Facebook chat session with the researchers.

\subsubsection{Austria-Land Use Effects}

After an initial call by the Austrian Center for Citizen Science in early 2016, 41 schools, 4 farmer groups, and 16 individual farmers were selected to participate in the Austrian Citizen Science Award mass experiment. Pre-weighed tea bags and an instruction booklet (http://www.teatime4science.org/ publications/\#lesson-plans) were sent to the citizen scientists in late May-early June 2016. An infographic provided a quick guide on how to carry out the experiment (https:/teatime4schools.at/tea-bag-index/). The citizen scientists started the experiment in early to mid-June 2016.

In the Austrian experiment, participants were asked to test the effect of land use. The citizen scientists buried three green and three rooibos bags in a freely selected land use type (maize field, forest, or grassland) following the standard TBI protocol. The participants at each study site took a soil sample with a spade from 0-10 cm depth. A background information data sheet (e.g., length of land use, possible fertilization and climatic data) was filled out at each site and sent back to the researchers.

In early-mid-September 2016 the experiment was completed and approximately half of the participants successfully returned their tea bags, soil samples, and background information sheets. Thereafter, the scientists weighed the tea bags and analyzed the soil samples. In total, 101 maize fields, 44 forest sites, and 33 grassland sites were investigated across Austria. Feedback was provided to the citizen scientists in a final workshop and the final presentation was shared through a webpage.

\subsection{Soil and Environmental Conditions}

\subsubsection{Soil Characterization}

Total soil organic carbon (SOC) concentrations of each soil sample in both Sweden and Austria were analysed by dry combustion (on ground samples in Sweden: FLASH 2000 Organic Elemental 
Analyzer; Interscience instruments; Breda; the Netherlands; and on sieved ( $<2 \mathrm{~mm})$ samples in Austria: LECO RC-612 TruMac CN (LECO Corp., St. Joseph, MI, USA at $650{ }^{\circ} \mathrm{C}$ (ÖNORM L1080)).

\subsubsection{Environmental Conditions}

We collected mean air temperature and summed precipitation for each sample location in Sweden and Austria from existing data sources. In Sweden, reanalysis of data on air temperature, precipitation, wind speed, and cloud cover (total, low clouds, medium clouds) were extracted as GRIB files from the public data base of the Swedish Meteorological and Hydrological Institute [21]. The data were produced by the MESoscale ANalysis system (MESAN) [22], which is based on the synoptic-scale HIgh-Resolution Limited-Area model (HIRLAM) [23]. GRIB data were available on a two-dimensional $0.05^{\circ}$ grid mesh (ca. $2.5 \times 2.5 \mathrm{~km}^{2}$ ) in a rotated geocentric Cartesian coordinate system (South Pole: lon $=-10$, lat $=-30$ ). This grid was rotated to a conventional geodetic coordinate system (World Geodetic System, WGS84) using transformation functions given by Swedish Meteorological and Hydrological Institute (SMHI) [21]. After subsampling GRIB data for synoptic times $(0 \mathrm{~h}, 6 \mathrm{~h}, 12 \mathrm{~h}$, $18 \mathrm{~h}$ ), school-specific weather data were extracted from the grid cell that intersected with the GPS coordinates of the school. Based on school-specific start and stop dates of the teabag incubation period, time series of weather data were extracted. These time series were then summarized by the following statistical measures for the purpose of this study: arithmetic mean values of air temperature and sum of precipitation. All GRIB data were handled using the nctoolbox [24] in Matlab $2015 \mathrm{~b}$ (The MathWorks Inc., Natick, MA, USA).

In Austria, the time series of environmental conditions were received from the Central Institution for Meteorology and Geodynamics (ZAMG), specifically from their weather stations that were closest to the investigated sites. The following statistical measures were used in this study: arithmetic mean values of air temperature and sum of precipitation, both based on the specific start and stop dates of the tea bag incubation periods as was done in Sweden.

\subsection{Citizen Scientist Motivations}

In both mass experiments, questionnaires were sent out shortly after finishing the experiment. In Sweden, they consisted of 27 questions for teachers and 8 questions for pupils. In Austria, the questionnaire consisted of 20 questions for the citizen scientist contact persons (teachers, farmers, or farmer group leaders). The questionnaires aimed to collect information on how the general procedure was experienced by citizen scientists, if the teachers found the project helpful for their teaching and, in Sweden, if pupils learned anything from participating or if it had affected participants' general attitudes towards science. From these questionnaires we selected questions dealing with: (i) how the citizen scientists heard about Tea Bag Index, (ii) why they signed up, (iii) how they would describe the experiment, and (iv) what they would change.

\subsection{Statistical Analyses}

The statistical analyses of $k$ and $S$ between warming and land use treatments were performed using the IBM SPSS Statistics 22 software package. The normality of data was checked with Shapiro-Wilk's test and their descriptive statistics were calculated. Effects of warming and land use per environmental zone were investigated with ANOVA with Tukey's significance test $(p<0.05)$ as a post-hoc test. Correlations between variables were presented in Pearson correlation coefficients. 


\section{Results}

\subsection{Citizen Science Experiments}

\subsubsection{Sweden-Warming Effects}

Almost all participants managed to start the experiment, but due to damaged field sites, changes of teachers, and other unforeseen circumstances and mistakes, only about half of the participants sent in data. The average decomposition rates of the labile fraction $(k)$ in Sweden ranged from 0.008 to $0.012 \mathrm{~g} \mathrm{~d}^{-1}$ (Table 1). No statistically significant differences were observed in the initial decomposition rates $(k)$ and stabilization factors (S) between warming and control treatments in any of the environmental zones investigated in Sweden (Figure 1). The initial decomposition rates ranged from $0.008 \mathrm{~g} \mathrm{~d}^{-1}$ in Alpine North to $0.012 \mathrm{~g} \mathrm{~d}^{-1}$ in Nemoral. The stabilization factors ranged from 0.32 to 0.35 in Alpine North and from 0.37 to 0.40 in the Continental environmental zone. Furthermore, soil temperature did not affect the results.

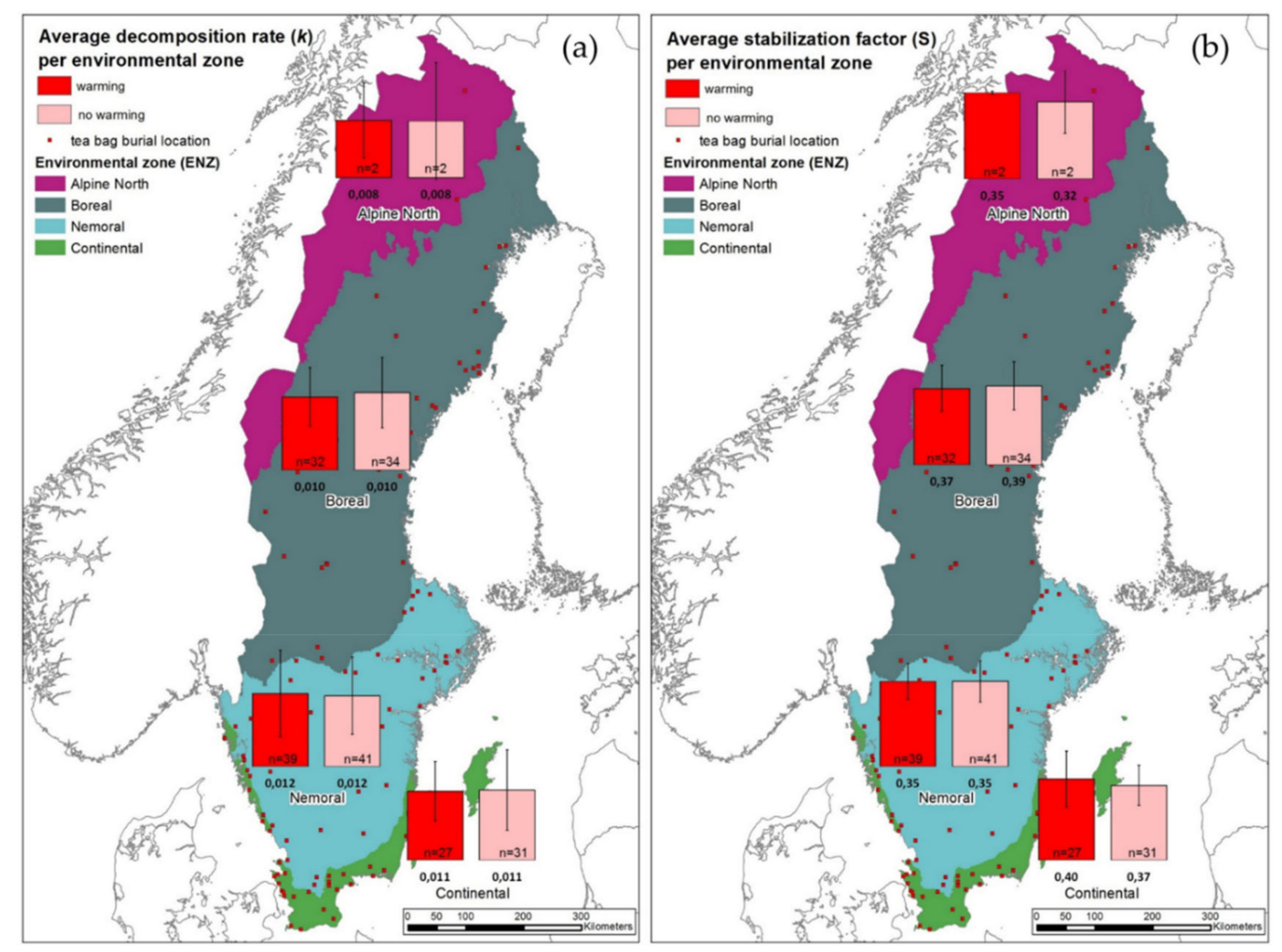

Figure 1. Swedish results on (a) initial decomposition rates $(k),(\mathbf{b})$ stabilization factors $(S)$. Error bars: standard deviation. 
Table 1. Summarized general environmental and soil parameters of the studied environmental zones. Different letters: significant difference between the environmental zones within one country. The Swedish results were combined from control and warmed plots and the Austrian results combined from different land uses (maize fields, grasslands, and forests).

\begin{tabular}{|c|c|c|c|c|c|c|c|c|}
\hline ENZ & & Air Temperature & Precipitation & & SOC & & $k$ & $S$ \\
\hline Sweden & $\mathrm{n}$ & ${ }^{\circ} \mathrm{C}(95 \% \mathrm{CI})$ & $\mathrm{mm}(95 \% \mathrm{CI})$ & $\mathrm{n}$ & $\mathrm{g} \mathrm{kg}^{-1}(95 \% \mathrm{CI})$ & $\mathrm{n}$ & $\mathrm{g} \mathrm{d}^{-1}(95 \% \mathrm{CI})$ & $(95 \% \mathrm{CI})$ \\
\hline Alpine North & 4 & $11.9(11.1-12.8) \mathrm{a}$ & 207 (145-269)cd & 2 & $5.49(-1.94-12.91)$ & 4 & $0.008(0.003-0.014)$ & $0.33(0.23-0.44)$ \\
\hline Boreal & 66 & $13.3(13.1-13.5) b$ & $173(158-189) \mathrm{c}$ & 50 & $4.77(3.29-6.26)$ & 66 & $0.010(0.008-0.011)$ & $0.38(0.36-0.41)$ \\
\hline Nemoral & 80 & $15.2(15.0-15.4) \mathrm{c}$ & $113(99.3-127) b$ & 69 & $7.28(6.02-8.54)$ & 80 & $0.012(0.010-0.013)$ & $0.35(0.33-0.37)$ \\
\hline Continental & 58 & $15.8(15.6-16.1) d$ & $76.6(60.3-92.8) \mathrm{a}$ & 56 & $5.91(4.51-7.32)$ & 58 & $0.011(0.010-0.013)$ & $0.38(0.35-0.41)$ \\
\hline ENZ & & Air Temperature & Precipitation & & SOC & & $k$ & $\mathrm{~S}$ \\
\hline Austria & $\mathrm{n}$ & ${ }^{\circ} \mathrm{C}(95 \% \mathrm{CI})$ & $\mathrm{mm}(95 \% \mathrm{CI})$ & $\mathrm{n}$ & $\mathrm{g} \mathrm{kg}^{-1}(95 \% \mathrm{CI})$ & $\mathrm{n}$ & $\mathrm{g} \mathrm{d}^{-1}(95 \% \mathrm{CI})$ & $(95 \% \mathrm{CI})$ \\
\hline Alpine South & 11 & $19.4(18.9-19.9) a$ & $324(278-370) \mathrm{b}$ & 11 & $2.82(0.93-4.71)$ & 11 & $0.015(0.012-0.018)$ & $0.08(0.04-0.13) \mathrm{a}$ \\
\hline Continental & 97 & 18.8 (18.6-19.0)a & $365(350-381) b$ & 97 & $3.40(2.76-4.03)$ & 97 & $0.013(0.012-0.015)$ & $0.14(0.13-0.16) \mathrm{b}$ \\
\hline Pannonian & 67 & $20.0(19.8-20.2) b$ & 196 (178-215)a & 67 & $2.31(1.55-3.08)$ & 67 & $0.012(0.010-0.013)$ & $0.14(0.12-0.15) \mathrm{ab}$ \\
\hline
\end{tabular}




\subsubsection{Austria-Land Use Effects}

The average decomposition rates of the labile fraction $(k)$ varied from 0.012 to $0.015 \mathrm{~g} \mathrm{~d}^{-1}$ in Austria (Table 1). Stabilization (S) of the labile fraction of green tea was up to four times higher in Sweden compared to Austria (Table 1). In the Pannonian environmental zone litter decomposition rates were significantly affected by land use, with highest rates in grasslands (Figure 2). Although differences were consistent in the Continental and Alpine South environmental zones, no statistically significant effects were observed between land uses there. Stabilization factors, however, were significantly higher in forests than in grasslands and maize fields in both Continental and Alpine South zones. We found a consistent pattern in the Pannonian zone, but it was not significant there.
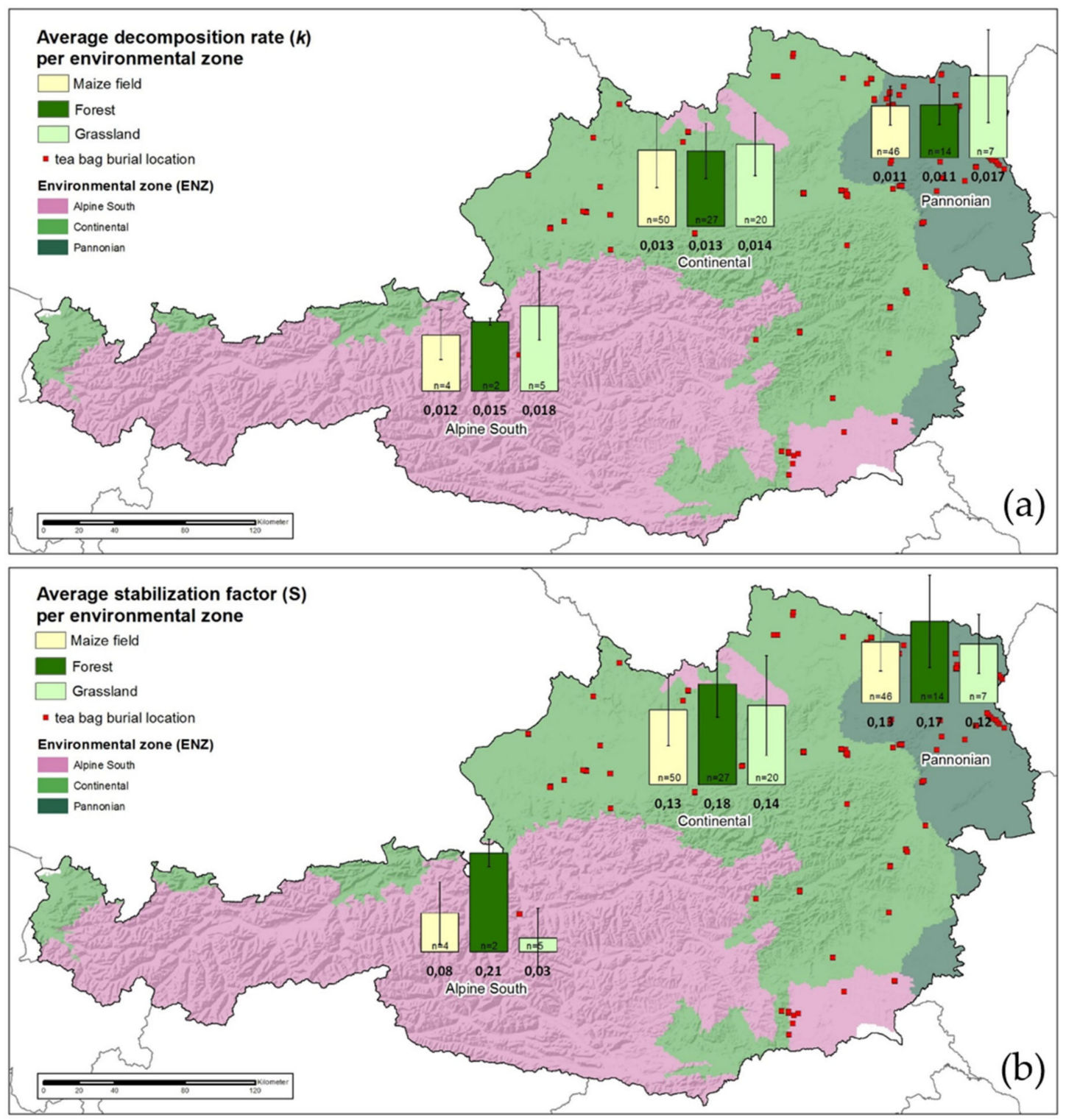

Figure 2. Austrian results on (a) initial decomposition rates $(k)$, (b) stabilization factors (S). Error bars denote standard deviation.

\subsubsection{Soil and Environmental Conditions}

The average air temperature during the experiment in Sweden ranged from $11.9^{\circ} \mathrm{C}$ to $15.8{ }^{\circ} \mathrm{C}$, in Austria from $19.4{ }^{\circ} \mathrm{C}$ to $20.0{ }^{\circ} \mathrm{C}$ (Table 1). Total precipitation during the experiment increased from South to North (Continental to Alpine North) in Sweden and from East to West (Pannonian to 
Alpine South) in Austria. The SOC contents were nearly two times higher in Sweden than in Austria, but the differences between the environmental zones within one country were not significant. We observed a significant negative correlation between stabilization factors and SOC in Sweden $(r=-0.201$, $p<0.01)$, and a significant positive correlation between decomposition rates and precipitation in Austria $(r=0.281, p<0.01)$. When analyzing all of the data together, $\mathrm{S}$ and SOC had a significant positive correlation $(r=0.195, p<0.01)$ and significant negative correlations were recorded between $\mathrm{S}$ and average temperature during the incubation $(r=-0.721, p<0.01)$ as well as between $S$ and the total precipitation during the incubation $(r=-0.494, p<0.01)$. Decomposition rates were significantly negatively correlated with latitude $(r=-0.189, p<0.01)$, and positively with both average temperature $(r=0.141, p<0.01)$ and total precipitation during the incubations $(r=0.218, p<0.01)$.

\subsection{Citizen Scientist Motivations}

The evaluation form was filled in by 65 teachers and 208 pupils in Sweden and by 11 citizen scientist contact persons in Austria. The average age of respondents was 48 and 12 years for teachers and pupils in Sweden, respectively. In Austria, 55\% of the respondents were $41-60$ years old, 27\% 26-40 years old, 9\% 18-25 old, and 9\% >60 years old. The participants had heard about the mass experiments from various sources (Figure 3): some had already participated in previous mass experiments in Sweden (other than the Tea Bag Index), whereas others had become aware of the mass experiments through newsletters, colleagues, friends, school directors, or they had found the information on the Internet or in a farmer's journal (in Austria). The main reasons to participate were to be part of a real, global research project, to work with an interesting research question as well as the simplicity of the required task. Especially for the schools in both Sweden and in Austria, important aspects were the willingness of students to participate and that the task was easy to incorporate into the curriculum. Positive experience from previous mass experiments (in Sweden) was also seen as a motivation to participate again. The participation was mainly described with positive words such as exciting, inspiring, cool, interesting, easy, and educational. Approximately $20 \%$ of the Swedish pupils also described the experiment as boring, weird, and complicated. Recommendations that came up via the evaluation forms included more information and communication between the participants during the three-month incubation time, even more clear instructions, and more feedback on what happened to the data after the experiment. 


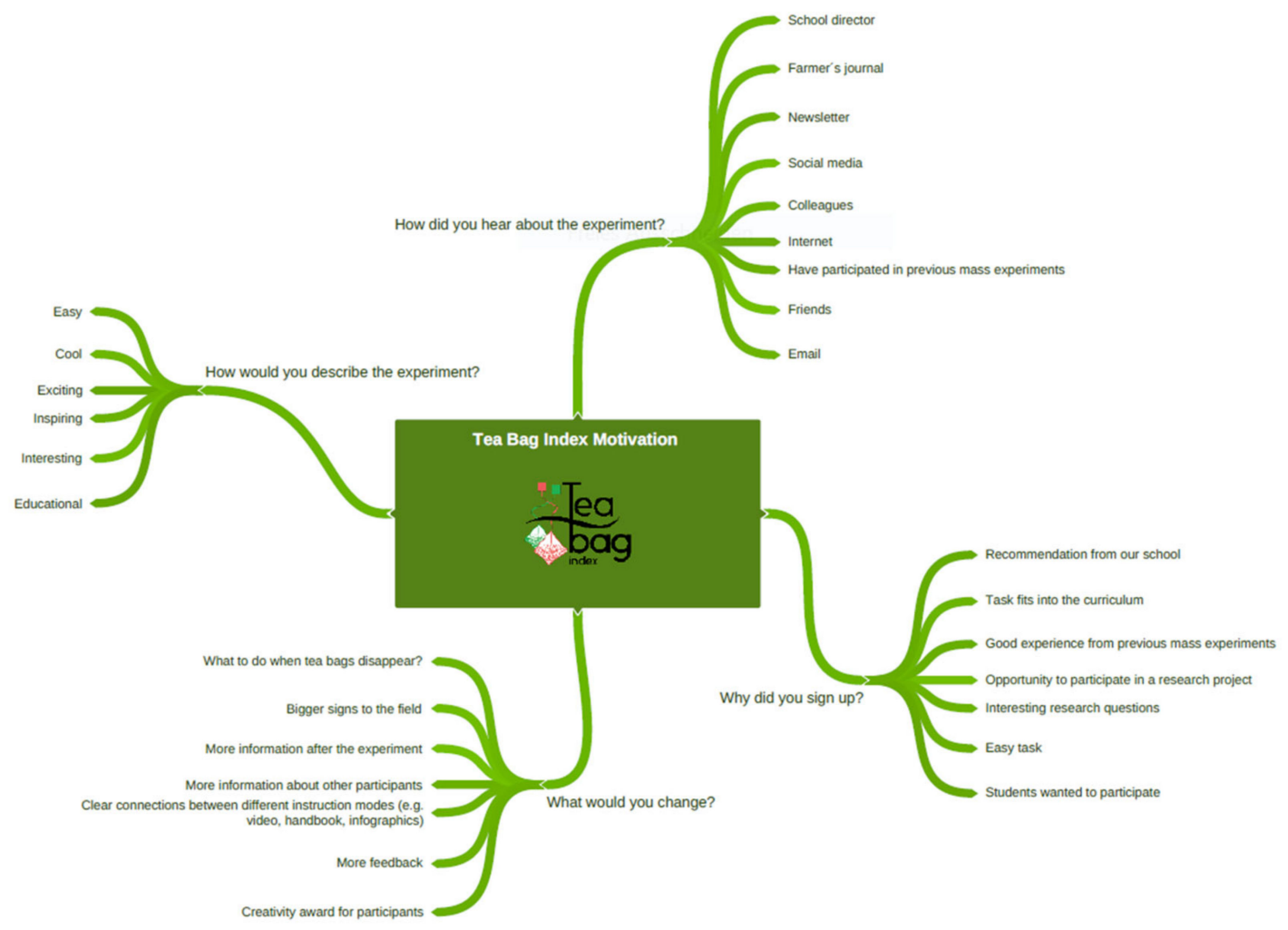

Figure 3. Citizen scientist responses to questions about their motivations. "How would you describe the experiment?" was answered by both pupils and teachers in Sweden, whereas the other questions were answered only by teachers. In Austria, the citizen scientists' contact persons answered all of the questions (using http://coggle.ie).

\section{Discussion}

\subsection{Decomposition}

The results from the two mass experiments were well within the range of global Tea Bag Index results obtained previously [7]. As expected, the sites in Sweden had lower $k$ and higher $S$ compared to the Austrian sites, which indicates slower and less decomposition in these colder and often less nutrient-rich soils. In the whole dataset, the climatic factors, including average temperature and total precipitation during the incubation period, were positively correlated with decomposition rates and negatively with stabilization factors. This is consistent with previous literature describing that colder and dryer climates result in less decomposition $[7,17,18]$. The fact that decomposition rates were negatively affected by latitude may be due to the negative correlation of latitude with temperatures and nutrient availability [25]. The stabilization factors were higher with increased SOC contents, but only when all sites in both countries were investigated together.

The TBI method was designed as a simple way to study litter decomposition that could easily be adapted for citizen scientists [7]. Our results show that, despite a considerable amount of failed experiments, citizen scientists collected valuable, good-quality data in accordance with previous literature (e.g., $[8,26])$. We found less warming effects than expected. Whereas warming experiments using passive warming such as tents, open top chambers, plexiglass corners, and our equivalent of plastic rings generally increase air temperatures by $0.8{ }^{\circ} \mathrm{C}$, the effects on soil temperature are more variable [27]. This is because factors such as drying and shading in temperature-stimulated vegetation can substantially alter soil temperatures. Such effects may also have diminished the effect of our PET rings on soil temperatures, potentially explaining the absence of a treatment effect on litter decomposition. 
For the land use treatments in Austria, our results (faster decomposition in grasslands and higher stabilization in forests) support previous findings and fit with the high carbon storage potential of forests [28]. The fact that these trends were not significant in all environmental zones may reflect interactions with climate (e.g., another factor beyond soil quality is limiting decomposition) or an uneven distribution of sites between the land uses, which may have overestimated our statistics. Note, [29] also found limited fertilization effects on tea bag decomposition across seven temperate grasslands, although their results also may partly have been attributed to their long incubation period compared to our standardized 90 days.

\subsection{Citizen Scientist Motivations}

When planning for efforts with citizen scientists—-both short-term in a sampling campaign and long-term in a continuous cooperation effort-it is essential to ensure that the project fulfills or plans to fulfill the ten principles of citizen science [30]. This helps guarantee, among other things, new knowledge generation with a genuine scientific outcome, that both participating citizen scientists and researchers benefit, and that there is a flow of information and feedback between the two groups. In both described TBI experiments, the citizen scientists were actively involved in generating new scientific knowledge and the projects had a genuine science outcome. Here, the citizen scientists mainly acted in data collection roles that positioned the project at the lowest crowdsourcing level of citizen science [31]. The roles were expanded in Sweden by doing a warming experiment and in Austria by comparing different land uses. In addition, the Swedish citizen scientists were sent a scale with which they could weigh tea bags themselves, compared to citizen scientists getting pre-weighed tea bags in Austria and sending the dried tea bags back to the researchers (insufficient budget to purchase scales for all participants). This resulted in more ways to engage citizen scientists in the Swedish project, although this required more researcher time to go through the data quality. In Austria, more uniform data were generated because the same team of researcher weighed the tea bags before and after burial. The ten principles of citizen science suggest that the citizen scientists should be included in formulating the research questions [31] and that they should be given opportunities to join the project later on. The researchers formulated the research questions in both Sweden and Austria. Although hypothesis building was already introduced in the instruction folder, the citizen scientists were offered continuous cooperation and they were able to get further involved in follow-up activities. Based on the questionnaires, we showed that citizen scientists benefited from the activities by gaining new experiences in hands-on science. Researchers benefited by an increased number of data points from both countries. Feedback to participants was provided in both countries in the forms of reports and presentations, in Sweden an additional Facebook meet-and-greet was organized, while in Austria the participants got the opportunity to meet one another in a workshop before and after the project activities. Such personal contacts have been shown to increase data quality [13]. This was highlighted in the Swedish Facebook page, where problems that were encountered during the experiment were discussed among participants and researchers. We experienced that decomposition data collection with citizen scientists comes with the same pros and cons as with scientific litterbag studies, including losing tea bags during the incubation time or roots growing into the tea bags. This remark is supported by the Tea Bag Index-UK project [32]. Engaged teachers or group leaders supported the successful experiments. Some citizen scientists were unable to complete their experiment because they could not find the tea bags after 90 days or the tea bags had broken after the burial. The data quality was verified in a similar manner as with data from other scientists and the results were calculated with the same standard calculation sheet as that provided to other researchers by the project [7]. Beyond data verification, the quality of the data was improved by training and introductory courses about soil, by close supervision of participating pupils by their teachers, and by the possibility to contact the scientists when questions arose. A further principle of citizen science is open access data and that the citizen scientists are acknowledged for their work. All data from our TBI experiments will be open access upon publication and the list of acknowledgements online 
(http://www.teatime4science.org/about/acknowledgements/) is updated regularly. The post-study questionnaires in both countries yielded important knowledge on the citizen scientists' motivations. In the future, it would be advisable to engage social science and education experts in formulating preand post-questionnaires $[33,34]$ in order to better grasp learning outcomes. The legal and ethical issues were taken into consideration in both cases by approving the workflow at the legal departments of the responsible organisations. Devictor et al. [35] sums up the citizen science success factors in five key terms: simplicity, scheme, feedback, communication, and sustainability. Except for the last one, these are well captured in the ten principles of citizen science [30]. Including sustainability, namely the continuous possibility to contribute to a project and to obtain updated information, is highly desirable, but may be difficult when projects are dependent on short-term funding [12]. To this end, however, both the Swedish Facebook page and the Austrian network continue to be provided with updates when relevant events occur (such as the soil temperature data being used in another global meta-analysis), or when a presentation of their results to a specific group of stakeholders is being posted.

\subsection{Future Prospects}

The TBI experiments in both Sweden and Austria can be classified as curriculum-based citizen science projects, including an active involvement of teachers, which further promotes the pupils' learning outcomes of participation [36]. By activating even more TBI citizen scientists in the future, TBI experiments could generate a great amount of soil awareness and new knowledge. This would also create new active research and demonstration sites that could serve as an arena for multi-stakeholder research, learning, and communication. This has been done previously in the citizen science networks OPAL [37], weather [38], and biodiversity [35,39]. Background data evidence for decision-making often comes from studies done a few decades ago [40], even though an enormous number of citizen science projects are available as enablers for up-to-date multidisciplinary information (e.g., [41]). Scientific experiments are costly to run and maintain, and the continuous collaboration and updating of data storage and infrastructure depends highly on funding opportunities. In order to have a well-functioning network of dedicated research sites across the whole globe, we should encourage cooperation with citizen science groups such as school or farmers' networks, supported by highly standardized research protocols. Our study shows that this is achievable, and improved cooperation with both educational and farming networks could scale it up. Bringing research closer to society is a challenge but also a great opportunity. One way to bridge the gap is to conduct further studies like the current one. Including emerging technologies such as mobile applications or interactive online platforms could further improve inclusion of different stakeholder groups and communication between citizen science actors [42]. The TBI experiments have already been done across the world [7] and encompassed ecosystems ranging from the tropics to the arctic and from the sea to mountain tops [43]. Importantly, several of them with active citizen scientist participation and engagement [44-46]. In case the specific tea required for the experiments is not available locally, links to web shops with global distribution are available on the project webpage (http://www.teatime4science.org/method/availability-of-tea/). This underlines that the methodology is simple enough to be used in different environments and it can generate valuable data for research. Moreover, it boosts scientific learning among the general public, as has been demonstrated in the Long Term Socio-Ecological Research platform (LTSER) "Zone Atelier Plaine \& Val de Sèvre" [47].

\section{Conclusions}

Our study successfully collected standardized data on litter decomposition in mass experiments in Sweden and in Austria, showing that citizen science can greatly contribute to generating new scientific knowledge on soils and help increase soil awareness among the general public. The geographical spread of measurements would not have been possible without the wide network of active schools and other stakeholders. Decomposition rates and stabilization factors were mainly governed by precipitation and temperature during the incubation. Moreover, SOC was positively correlated with 
stabilization factors, whereas decomposition rates were negatively correlated with latitudes. The effect of warming was not significant in Sweden but land use showed significant effects in Austria, especially on stabilization factors. Importantly, these patterns are in line with studies conducted by trained researchers. Beyond introducing citizen scientists to research in a playful manner, the project visualized soil processes which helped to increase soil awareness. The feedback from the participants showed that the TBI activities were easy to integrate into regular school and farm activities. This provides encouragement for further efforts in adjusting TBI activities such that they serve the stakeholders' needs, including the wish for continuous feedback and information, promoting life-long learning for the participants.

Author Contributions: This article resulted from a cooperation within the Tea Bag Index team (http://www. teatime4science.org/). Conceptualization, T.S. and J.M.S.; data curation, T.S. and J.M.S.; formal analysis, T.S. and J.M.S.; funding acquisition, J.M.S.; investigation, T.S. and J.M.S.; methodology, T.S. and J.M.S.; project administration, T.S. and J.M.S.; resources, H.S.; validation, T.S. and J.M.S.; visualization, T.S. and M.S.; writing-original draft, T.S., H.S., H.W., M.S. and J.M.S.; writing - review and editing, T.S. All authors have read and agreed to the published version of the manuscript.

Funding: Judith Sarneel acknowledges Vetenskapsrådet for funding (2014-04270) and Lenka Kuglerova and Eliza Hasselquist for providing temperature loggers.

Acknowledgments: We acknowledge the $>5500$ citizen scientists in Sweden and Austria that made this research possible (for full list of participants: http://www.teatime4science.org/about/acknowledgements/). Fredrik Brounéus from VA, Public and Science, is acknowledged for coordinating the school contacts in Sweden. Marcus Klaus is acknowledged for help with calculating the Swedish weather data. Iris van Hamersveld and Gerrit Rauwenhorst for practical help in the lab in Sweden. Taru Sandén acknowledges the Austrian Citizen Science Award 2016 from the Zentrum für Citizen Science for including Tea Bag Index as one of the advertised projects (https://www.zentrumfuercitizenscience.at/de/citizen-science-awards-2016) as well as Katharina Seper, Tamara Schwach and Sophie Seiler for help in the field and in the lab. Michael Stachowitsch is acknowledged for English proofreading.

Conflicts of Interest: The authors declare no conflict of interest.

\section{References}

1. Schulte, R.P.O.; Creamer, R.E.; Donnellan, T.; Farrelly, N.; Fealy, R.; O'Donoghue, C.; O'hUallachain, D. Functional land management: A framework for managing soil-based ecosystem services for the sustainable intensification of agriculture. Environ. Sci. Policy 2014, 38, 45-58. [CrossRef]

2. Robinson, D.A.; Panagos, P.; Borrelli, P.; Jones, A.; Montanarella, L.; Tye, A.; Obst, C.G. Soil natural capital in europe; a framework for state and change assessment. Sci. Rep. 2017, 7, 6706. [CrossRef]

3. Jackson, R.B. The Ecology of Soil Carbon: Pools, Vulnerabilities, and Biotic and Abiotic Controls. Annu. Rev. Ecol. Evol. Syst. 2017, 48, 419-445. [CrossRef]

4. Schlesinger, W.H. Evidence from chronosequence studies for a low carbon-storage potential of soils. Nature 1990, 348, 232-234. [CrossRef]

5. Harden, J.W.; Hugelius, G.; Ahlström, A.; Blankinship, J.C.; Bond-Lamberty, B.; Lawrence, C.R.; Loisel, J.; Malhotra, A.; Jackson, R.B.; Ogle, S.; et al. Networking our science to characterize the state, vulnerabilities, and management opportunities of soil organic matter. Glob. Chang. Biol. 2018, 24, e705-e718. [CrossRef] [PubMed]

6. Don, A.; Böhme, I.H.; Dohrmann, A.B.; Poeplau, C.; Tebbe, C.C. Microbial community composition affects soil organic carbon turnover in mineral soils. Biol. Fertil. Soils 2017, 53, 445-456. [CrossRef]

7. Keuskamp, J.A.; Dingemans, B.J.J.; Lehtinen, T.; Sarneel, J.M.; Hefting, M.M. Tea Bag Index: A novel approach to collect uniform decomposition data across ecosystems. Methods Ecol. Evol. 2013, 4, 1070-1075. [CrossRef]

8. Rossiter, D.G.; Liu, J.; Carlisle, S.; Zhu, A.X. Can citizen science assist digital soil mapping? Geoderma 2015, 259-260, 71-80. [CrossRef]

9. Cohn, J.P. Citizen Science: Can Volunteers Do Real Research? BioScience 2008, 58, 192-197. [CrossRef]

10. Gardiner, M.M.; Allee, L.L.; Brown, P.M.; Losey, J.E.; Roy, H.E.; Smyth, R.R. Lessons from lady beetles: Accuracy of monitoring data from US and UK citizen-science programs. Front. Ecol. Environ. 2012, 10, 471-476. [CrossRef] 
11. Lobry de Bruyn, L.; Jenkins, A.; Samson-Liebig, S. Lessons Learnt: Sharing Soil Knowledge to Improve Land Management and Sustainable Soil Use. Soil Sci. Soc. Am. J. 2017, 81, 427-438. [CrossRef]

12. Dickinson, J.L.; Shirk, J.; Bonter, D.; Bonney, R.; Crain, R.L.; Martin, J.; Phillips, T.; Purcell, K. The current state of citizen science as a tool for ecological research and public engagement. Front. Ecol. Environ. 2012, 10, 291-297. [CrossRef]

13. Kosmala, M.; Wiggins, A.; Swanson, A.; Simmons, B. Assessing data quality in citizen science. Front. Ecol. Environ. 2016, 14, 551-560. [CrossRef]

14. Zhao, Y.; Feng, D.; Yu, L.; See, L.; Fritz, S.; Perger, C.; Gong, P. Assessing and Improving the Reliability of Volunteered Land Cover Reference Data. Remote Sens. 2017, 9, 1034. [CrossRef]

15. Foody, G.; See, L.; Fritz, S.; Moorthy, I.; Perger, C.; Schill, C.; Boyd, D. Increasing the Accuracy of Crowdsourced Information on Land Cover via a Voting Procedure Weighted by Information Inferred from the Contributed Data. ISPRS Int. J. Geo-Inf. 2018, 7, 80. [CrossRef]

16. Berg, B.; Meentemeyer, V. Litter quality in a north European transect versus carbon storage potential. Plant Soil 2002, 242, 83-92. [CrossRef]

17. Trofymow, J.A.; Moore, T.R.; Titus, B.; Prescott, C.; Morrison, I.; Siltanen, M.; Smith, S.; Fyles, J.; Wein, R.; Camiré, C.; et al. Rates of litter decomposition over 6 years in Canadian forests: Influence of litter quality and climate. Can. J. For. Res. 2002, 32, 789-804. [CrossRef]

18. Parton, W.; Silver, W.L.; Burke, I.C.; Grassens, L.; Harmon, M.E.; Currie, W.S.; King, J.Y.; Adair, E.C.; Brandt, L.A.; Hart, S.C.; et al. Global-Scale Similarities in Nitrogen Release Patterns During Long-Term Decomposition. Science 2007, 315, 361-364. [CrossRef]

19. Bonan, G.B.; Hartman, M.D.; Parton, W.J.; Wieder, W.R. Evaluating litter decomposition in earth system models with long-term litterbag experiments: An example using the Community Land Model version 4 (CLM4). Glob. Chang. Biol. 2013, 19, 957-974. [CrossRef]

20. Stockmann, U.; Adams, M.A.; Crawford, J.W.; Field, D.J.; Henakaarchchi, N.; Jenkins, M.; Minasny, B.; McBratney, A.B.; Courcelles, V.d.R.d.; Singh, K.; et al. The knowns, known unknowns and unknowns of sequestration of soil organic carbon. Agric. Ecosyst. Environ. 2013, 164, 80-99. [CrossRef]

21. SMHI. Öppna Data-Modell-och Analysdata; SMHI: Norrkoping, Sweden, 2016.

22. Landelius, T.; Dahlgren, P.; Gollvik, S.; Jansson, A.; Olsson, E. A high-resolution regional reanalysis for Europe. Part 2: 2D analysis of surface temperature, precipitation and wind. Q. J. R. Meteorol. Soc. 2016, 142, 2132-2142. [CrossRef]

23. Dahlgren, P.; Landelius, T.; Kållberg, P.; Gollvik, S. A high-resolution regional reanalysis for Europe. Part 1: Three-dimensional reanalysis with the regional HIgh-Resolution Limited-Area Model (HIRLAM). Q. J. R. Meteorol. Soc. 2016, 142, 2119-2131. [CrossRef]

24. Schlining, B.; Crosby, A.; Signell, R. Nctoolbox 1.1.0; Github Repository. 2013. Available online: https: //github.com/nctoolbox/nctoolbox (accessed on 18 September 2020).

25. Marian, F.; Sandmann, D.; Krashevska, V.; Maraun, M.; Scheu, S. Leaf and root litter decomposition is discontinued at high altitude tropical montane rainforests contributing to carbon sequestration. Ecol. Evol 2017, 7, 6432-6443. [CrossRef] [PubMed]

26. Steinke, J.; van Etten, J.; Zelan, P.M. The accuracy of farmer-generated data in an agricultural citizen science methodology. Agron. Sustain. Dev. 2017, 37, 32. [CrossRef]

27. Bokhorst, S.; Huiskes, A.; Aerts, R.; Convey, P.; Cooper, E.J.; Dalen, L.; Erschbamer, B.; Gudmundsson, J.; Hofgaard, A.; Hollister, R.D.; et al. Variable temperature effects of Open Top Chambers at polar and alpine sites explained by irradiance and snow depth. Glob. Chang. Biol. 2013, 19, 64-74. [CrossRef]

28. Deng, L.; Zhu, G.-y.; Tang, Z.-s.; Shangguan, Z.-p. Global patterns of the effects of land-use changes on soil carbon stocks. Glob. Ecol. Conserv. 2016, 5, 127-138. [CrossRef]

29. Poeplau, C.; Zopf, D.; Greiner, B.; Geerts, R.; Korvaar, H.; Thumm, U.; Don, A.; Heidkamp, A.; Flessa, H. Why does mineral fertilization increase soil carbon stocks in temperate grasslands? Agric. Ecosyst. Environ. 2018, 265, 144-155. [CrossRef]

30. Robinson, L.D.; Cawthray, J.L.; West, S.E.; Bonn, A.; Ansine, J. Ten principles of citizen science. In Citizen Science: Innovation in Open Science, Society and Policy; Hecker, S., Haklay, M., Bowser, A., Makuch, Z., Vogel, J., Bonn, A., Eds.; UCL Press: London, UK, 2018; pp. 27-51. [CrossRef]

31. Haklay, M. Citizen Science and Volunteered Geographic Information: Overview and Typology of Participation. In Crowdsourcing Geographic Knowledge; Springer: Dordrecht, The Netherlands, 2013. 
32. Sui, D.Z.; Elwood, S.; Goodchild, M.F. (Eds.) Volunteered Geographic Information (VGI) in Theory and Practice; Springer: Berlin/Heidelberg, Germany, 2013; pp. 105-122. [CrossRef]

33. Duddigan, S.; Alexander, P.D.; Shaw, L.J.; Sandén, T.; Collins, C.D. The Tea Bag Index-UK: Using Citizen/Community Science to Investigate Organic Matter Decomposition Rates in Domestic Gardens. Sustainability 2020, 12, 6895. [CrossRef]

34. Kobori, H.; Dickinson, J.L.; Washitani, I.; Sakurai, R.; Amano, T.; Komatsu, N.; Kitamura, W.; Takagawa, S.; Koyama, K.; Ogawara, T.; et al. Citizen science: A new approach to advance ecology, education, and conservation. Ecol. Res. 2016, 31, 1-19. [CrossRef]

35. Kelemen-Finan, J.; Scheuch, M.; Winter, S. Contributions from citizen science to science education: An examination of a biodiversity citizen science project with schools in Central Europe. Int. J. Sci. Educ. 2018, 40, 2078-2098. [CrossRef]

36. Devictor, V.; Whittaker, R.J.; Beltrame, C. Beyond scarcity: Citizen science programmes as useful tools for conservation biogeography. Divers. Distrib. 2010, 16, 354-362. [CrossRef]

37. Bonney, R.; Phillips, T.B.; Ballard, H.L.; Enck, J.W. Can citizen science enhance public understanding of science? Public Underst. Sci. 2016, 25, 2-16. [CrossRef] [PubMed]

38. Davies, L.; Fradera, R.; Riesch, H.; Lakeman-Fraser, P. Surveying the citizen science landscape: An exploration of the design, delivery and impact of citizen science through the lens of the Open Air Laboratories (OPAL) programme. BMC Ecol. 2016, 16, 17. [CrossRef] [PubMed]

39. Gharesifard, M.; Wehn, U.; van der Zaag, P. Towards benchmarking citizen observatories: Features and functioning of online amateur weather networks. J. Environ. Manag. 2017, 193, 381-393. [CrossRef]

40. Theobald, E.J.; Ettinger, A.K.; Burgess, H.K.; DeBey, L.B.; Schmidt, N.R.; Froehlich, H.E.; Wagner, C.; HilleRisLambers, J.; Tewksbury, J.; Harsch, M.A.; et al. Global change and local solutions: Tapping the unrealized potential of citizen science for biodiversity research. Biol. Conserv. 2015, 181, 236-244. [CrossRef]

41. Montanarella, L.; Pennock, D.J.; McKenzie, N.; Badraoui, M.; Chude, V.; Baptista, I.; Mamo, T.; Yemefack, M.; Singh Aulakh, M.; Yagi, K.; et al. World's soils are under threat. SOIL 2016, 2, 79-82. [CrossRef]

42. Waldner, F.; Schucknecht, A.; Lesiv, M.; Gallego, J.; See, L.; Pérez-Hoyos, A.; d'Andrimont, R.; de Maet, T.; Bayas, J.C.L.; Fritz, S.; et al. Conflation of expert and crowd reference data to validate global binary thematic maps. Remote Sens. Environ. 2019, 221, 235-246. [CrossRef]

43. Newman, G.; Wiggins, A.; Crall, A.; Graham, E.; Newman, S.; Crowston, K. The future of citizen science: Emerging technologies and shifting paradigms. Front. Ecol. Environ. 2012, 10, 298-304. [CrossRef]

44. Mueller, P.; Schile-Beers, L.M.; Mozdzer, T.J.; Chmura, G.L.; Dinter, T.; Kuzyakov, Y.; de Groot, A.V.; Esselink, P.; Smit, C.; D'Alpaos, A.; et al. Global-change effects on early-stage decomposition processes in tidal wetlands-implications from a global survey using standardized litter. Biogeosciences 2018, 15, 3189-3202. [CrossRef]

45. Tresch, S.; Moretti, M.; Le Bayon, R.-C.; Mäder, P.; Zanetta, A.; Frey, D.; Fliessbach, A. A Gardener's Influence on Urban Soil Quality. Front. Environ. Sci. 2018, 6. [CrossRef]

46. Seelen, L.M.S.; Flaim, G.; Keuskamp, J.; Teurlincx, S.; Arias Font, R.; Tolunay, D.; Fránková, M.; Šumberová, K.; Temponeras, M.; Lenhardt, M.; et al. An affordable and reliable assessment of aquatic decomposition: Tailoring the Tea Bag Index to surface waters. Water Res. 2019, 151, 31-43. [CrossRef] [PubMed]

47. Bretagnolle, V.; Berthet, E.; Gross, N.; Gauffre, B.; Plumejeaud, C.; Houte, S.; Badenhausser, I.; Monceau, K.; Allier, F.; Monestiez, P.; et al. Towards sustainable and multifunctional agriculture in farmland landscapes: Lessons from the integrative approach of a French LTSER platform. Sci. Total Environ. 2018, 627, 822-834. [CrossRef] [PubMed]

(C) 2020 by the authors. Licensee MDPI, Basel, Switzerland. This article is an open access article distributed under the terms and conditions of the Creative Commons Attribution (CC BY) license (http://creativecommons.org/licenses/by/4.0/). 